\title{
DIREITOS À MEIA LUZ: REGULAMENTAÇÃO DO USO DO NOME SOCIAL DE ESTUDANTES TRAVESTIS E TRANSEXUAIS NAS INSTITUIÇÕES ESCOLARES
}

Jonas Alves da Silva Junior*

\begin{abstract}
RESUMO
O objetivo deste artigo é levantar, sistematizar e analisar os efeitos das legislações que regulamentam o uso do nome social de estudantes travestis e transexuais nas escolas brasileiras. Para isso, problematizaram-se as identidades trans (travestis e transexuais) no ambiente escolar, balizadas no diálogo entre as teorias de Michel Foucault e Judith Butler, dentre outros(as) autores(as). Como os processos de subjetivação se configuram em modos de normatização e de singularização que se estabelecem tanto no sujeito individual, como nos múltiplos espaços sociais em que este(a) vive, a ingerência na escola pode propiciar a re/construção das identidades num processo dinâmico e continuado, invariavelmente interpelado por dispositivos sociais e curriculares. Assim, recorremos aos estudos queer para buscar compreender a pluralidade sexual e de gênero no contexto escolar, uma vez que as experiências transexuais e travestis na escola são múltiplas e singulares. A pesquisa realizada evidenciou que as legislações e políticas públicas voltadas para a comunidade LGBT são precárias e insuficientes para garantir o acesso e permanência de travestis e transexuais na escola. Por isso, este artigo se encerra com uma reflexão sobre a urgência e a possibilidade de inclusão dos temas diversidade sexual e identidades de gênero na formação de professores (as) e, consequentemente, no cotidiano escolar.
\end{abstract}

Palavras-chave: Travesti. Transexual. Nome social. Gênero. Pedagogia queer.

\begin{abstract}
RIGHTS TO HALF LIGHT: USE REGULATION OF SOCIAL NAME OF TRANSGENDER AND TRANSVESTITES STUDENTS IN SCHOOL INSTITUTIONS The purpose of this article is to raise, organize and analyze the effects of the laws governing the use of the social name of transgender and transvestites students in Brazilian schools. For this, it was problematized the trans identities (transvestites and transgender) at the school environment, buoyed in the dialogue between the theories of Michel Foucault and Judith Butler, among other authors. As subjective processes are configured in modes of regulation and singling settled both in the individual subject, as in many social spaces where they live, the interference of the school can provide the construction of identities in a dynamic and continuous process invariably intermediated by social and curricular devices. Thus, we turn to queer studies to try to understand the sexual and gender plurality in the school context, since the transgender and transvestites
\end{abstract}

* Doutor em Educação pela Universidade de São Paulo (USP). Mestre em Letras pela Universidade de São Paulo (USP). Professor Adjunto do curso de Pedagogia da Universidade Federal Rural do Rio de Janeiro (UFRRJ). Endereço para correspondência: Rua Correa Dutra, 65, ap. 104. CEP: 22210-050 - Rio de Janeiro-RJ. Telefone: (21) 974779584. jonasjr@usp.br 
experience in school are multiple and singular. The research showed that public laws and policies aimed at the LGBT community are poor and insufficient to guarantee access and permanence of transvestites and transsexuals in school. Therefore, this article concludes with a reflection on the urgency and the possibilities for inclusion of issues such as sexual diversity and gender identities in teacher formation, hence in everyday school life.

Keywords: Transgender. Transvestites. Social name. Gender. Queer pedagogy.

\section{RESUMEN}

\section{DERECHOS A MEDIA LUZ: REGLAMENTACIÓN DEL USO DEL NOMBRE SOCIAL DE LOS ESTUDIANTES TRAVESTIS Y TRANSEXUALES EN INSTITUCIONES ESCOLARES}

El objetivo de este artículo es levantar, sistematizar y analizar los efectos de las leyes que rigen el uso de la denominación social de los travestis y transexuales estudiantes en las escuelas brasileñas. Para ello se problematizaron las identidades Trans (travestis y transexuales) en la escuela, enfocadas en el diálogo entre las teorías de Michel Foucault y Judith Butler, entre otras y otros autores. Cómo los procesos de subjetivación se configuran en modos de regulación y singularización que se establecen tanto en el sujeto individual, como en muchos espacios sociales donde este(a) vive, la interferencia en la escuela puede proporcionar la reconstrucción de las identidades en un proceso dinámico y continuo invariablemente interpelado por los dispositivos sociales y curriculares. Por lo tanto recurrimos a estudios los Queer para buscar comprender la pluralidad sexual y de género en el contexto escolar, ya que las experiencias transexuales y travestis en la escuela son múltiples y singulares. La investigación evidenció que las leyes y las políticas públicas dirigidas a la comunidad LGBT son pobres e insuficientes para garantizar el acceso y permanencia de travestis y transexuales en la escuela. Por lo tanto, este artículo concluye con una reflexión sobre la urgencia y las posibilidades de inclusión de temas de diversidad sexual e identidades de género en la formación de profesores(as) y consecuentemente en el cotidiano escolar.

Palabras claves: Travesti. Transexual. Nombre social. Género. Pedagogia queer.

\section{A escola no contexto da diversidade}

Infere-se da Constituição da República Federativa do Brasil, que "[...] a educação é um direito de todos e um dever do Estado [...]” (BRASIL, 1988). Com isso explicita-se um princípio da educação brasileira - a universalização do ensino. No entanto, pode-se compreender que esse discurso não tem se efetivado na prática, considerando-se a preocupação expressa nos vários programas de enfrentamento à evasão escolar, tais como: Plano de Desenvolvimento da Educação, Caminho da Escola, Pró-Escolar, Bolsa Família, Portal Aprendiz, Programa de Apoio ao Dirigente Municipal, Escola Aberta e Escola em Tempo Integral, Mais
Educação, dentre outros.

A evasão escolar expõe várias facetas, dentre elas a sexualidade, assinalada na maioria das falas das/dos travestis e transexuais quando perguntadas(os) sobre sua educação formal. É relevante notar que pesquisas quantitativas que abalizem dados irrefutáveis sobre a evasão escolar pertinentes ao preconceito e à discriminação dessas pessoas praticamente não existem. Contudo, são vários os estudos qualitativos baseados nos relatos dos sujeitos que denunciam ter vivenciado essas situações.

Com base em um recorte intencional, elegeu-se trabalhar com a população transexual no que tange ao preconceito, aqui entendido como ideia pré/ concebida acerca de algo, e a discriminação com- 
preendida nesse contexto como comportamentos e posturas que segregam sujeitos mediante suas diferenças em relação aos grupos hegemônicos.

Em várias mídias têm-se observado falas de transexuais que denunciam um sutil e perverso maquinário dentro das escolas públicas e privadas que, em pleno funcionamento, expulsa e mantém esses sujeitos fora da escola, quando esse espaço deveria ser garantido pelo princípio da universalização do ensino, com acesso e permanência de todas as pessoas na escola.

Uma das razões principais para essa extrusão tem relação com a insistência dos(as) educadores(as) se reportarem aos/às transexuais através de seu nome civil, registrado nos documentos oficiais, em detrimento do nome social escolhido pelo sujeito em concordância com a maneira como esse sujeito se reconhece, identifica e apresenta-se nas relações sociais.

Tanto no cenário nacional quanto estadual, as políticas públicas educacionais vêm apontando para a inclusão dos sujeitos ditos "diferentes" com igualdade de direitos na escola. Dessa forma, diversas táticas foram empregadas nos últimos anos com intuito de garantir a todos(as) o acesso e a permanência na escola. Os sujeitos que, por muito tempo, foram negligenciados nos discursos educacionais granjearam seus espaços. Em decorrência disso, múltiplas ações têm sido desenvolvidas e implementadas pensando na inclusão educacional e em uma escola que respeite as diferenças dos distintos sujeitos, seja no que tange à orientação sexual, religião, etnia ou raça, com a finalidade de afiançar as diretrizes nacionais da educação básica, no que diz respeito à democratização do ensino no Brasil. Os programas difundidos pelo Ministério da Educação têm evidenciado interesse em resolver a evasão escolar dos segmentos que, no decorrer de muito tempo, ficaram abaixo do processo educativo, potencializando a desigualdade social e, por conseguinte, a exclusão de sujeitos e classes. O acesso e permanência à educação são, na atualidade, direitos que foram angariados na Constituição Federal de 1988 e reafirmados na Lei no 9394/96, a Lei de Diretrizes e Bases da Educação Nacional - LDB (BRASIL, 1996).

O sistema educacional brasileiro, tal como o conhecemos hoje, data do século XX, como afir- ma Candau (2002). Nessa perspectiva, as muitas possibilidades de obtenção de conhecimento têm demandado da escola práticas pedagógicas diversificadas, já que o ensinar e o aprender não estão mais conectados às práticas tradicionais, o que nos leva a depreender que não cabe mais pensar nos(as) alunos(as) unificados(as), pois

[...] a cultura escolar está impregnada pela perspectiva do comum, do aluno padrão, do 'aqui todos são iguais'. No entanto, as escolas estão cada vez mais desafiadas a enfrentar os problemas decorrentes das diferenças e da pluralidade cultural, étnica, social, religiosa etc., dos seus sujeitos e atores. (CANDAU, 2002, p. 14, GRIFO DO AUTOR).

De acordo com Candau (2002), a escola é um espaço da diversidade, por isso não existe mais um arquétipo padronizado de alunos(as), mas sim uma gama de sujeitos com suas diferenças étnicas, raciais, de orientação sexual, de identidades e de gêneros diversos. Os movimentos sociais, historicamente, têm sido atores assaz importantes na re/significação das identidades, das culturas e conquista de direitos sociais. No entendimento de um Estado democrático de direitos, a escola também tem sido uma instância pensada e aventada, na perspectiva de uma instituição mais plural que congregue em seu currículo subsídios de distintas etnias e que, até mesmo, problematize os estereótipos sociais a respeito das identidades de gênero.

\section{A Pedagogia Queer}

Concretizar apontamentos sobre a experiência transexual e a escola ocasionou uma aproximação com a Teoria Queer. ${ }^{1}$ Esse referencial teórico baliza concepções pelas quais é possível problematizar a ideia da necessidade da classificação social fixa e binária e da obsessão pelas identidades sexuais, como impulsionadas pelas disciplinas e também pelo controle. A escola contemporânea não suporta lidar com a desestabilização das suas verdades e

1 De acordo com Louro (2004), o significado do termo queer está diretamente ligado aos sujeitos da sexualidade fora da norma heterossexual. Conforme a autora, "queer é tudo isso: é estranho, raro, esquisito. Queer é, também, o sujeito da sexualidade desviante - homossexuais, bissexuais, transexuais, travestis, drags. É o excêntrico que não deseja ser integrado e muito menos tolerado" (LOURO, 2004, p. 7). Para Silva (2007, p. 105), o termo queer pode ser entendido como "estranho, esquisito, incomum, fora do normal, excêntrico". 
a afasta produzindo e reiterando a norma, sucessivamente, para que possa classificar de forma mais ativa as nuanças entre os binarismos. De acordo com Swain (2009, p. 06):

Estou falando da interpretação binária do mundo, não somente em relação aos sexos, homem/mulher (na ordem), mas igualmente quanto à visão dualista do que compõe a inteligibilidade da vida: o bem e o mal, o bom e o mau, o real e o imaginário, o puro e o impuro, o claro e o obscuro, o verdadeiro e o falso, o belo e o feio, o espírito e a matéria, a vida e a morte. As filigranas, as nuances, que fazem o maravilhoso no desabrochar da vida são assim reduzidas ao silêncio e à monotonia de mais uma conexão binária: eu e o outro.

O que inquieta tanto a escola em relação a esses sujeitos? Seria a fabricação dos corpos? Seria a ambiguidade, a imprecisão? Seriam as verdades da escola no que se refere a esses corpos? Conforme César (2009, p. 48):

Alunas/os e professoras/es gays, lésbicas, bissexuais, [travestis] e transexuais compõem a diversidade contemporânea da instituição escolar; entretanto, para esta instituição que nasceu disciplinar e normatizadora, a diferença, ou tudo aquilo que está fora da norma, em especial, a norma sexual, mostra ser insuportável por transbordar os limites do conhecido.

O que se pensa como desafio é a compreensão a partir de um campo epistemológico e político desconhecido, levando em conta que o conhecido está engendrado na heteronormatividade compulsória. Faz-se importante pensar sobre as formas como a escola contemporânea estabeleceu-se em um espaço de controle e governo dos corpos e das mentes, gerando as normas regulatórias que amparam o sistema corpo-sexo-gênero e, por meio das teorizações queer, também investigar os imperativos heteronormativos que arquitetam os processos de exclusão (BUTLER, 2003).

Travestis e transexuais concretizam o funcionamento da escola como uma engenharia biopolítica em que permanecem, em geral, os corpos e as subjetividades almejáveis, isto é, heterossexuais e normalizados ou não-heterossexuais camuflados. Aos outros corpos e subjetividades cria-se um posicionamento exterior à instituição escolar, por meio de discursos e práticas pedagógicas que, quando bem engendradas, resultam, com sucesso, na expulsão dos sujeitos "anormais" para a garantia de estabilidade dos normalizados. Como a escola se constituiu em uma engrenagem da máquina normativa de exclusão sistematizada de travestis e transexuais? (CÉSAR, 2008). A concepção de racismo, ligado à biologia, elaborado por Foucault (2008), ao examinar a emergência do biopoder é cabal para se refletir sobre esses processos. Dessa forma, nas investigações de Silvio Gallo (2009, p. 36):

Na medida em que não suportamos a sensação de estrangeiridade, é necessário encontrar elementos para justificar e suportar o processo de apagamento das diferenças. Os mecanismos de exclusão que permeiam o cotidiano da escola fundam-se em relações de racismo, como meio de justificar que o outro (o anormal, aquele que escapa da norma) deve ficar de fora. No cotidiano da escola, as relações de exclusão pelo racismo colocam-se para muito além da questão de raça, mas trespassam as questões de gênero e de sexualidade, como formas de violência física e simbólica.

Assim, o racismo pode ser compreendido como um poder de corte, de ascensão de um segmento da população, segregando, normatizando, controlando e, quando necessário, marginalizando aquelas(es) que desviam demais da norma, que não conseguem ser normalizadas(os). Essa exclusão justifica-se pela proteção e garantia dos direitos para os que permanecem na norma (CÉSAR, 2009; GALLO, 2009). Dessa forma, poder-se-ia perguntar sobre o que a escola enxerga nesses corpos e identidades, produzindo a exclusão desses sujeitos? De acordo com Butler (2000), esses corpos são abjetos, materializados por meio da ordem heterossexual no domínio do inumano, portanto, não importando, não pesando e podendo ser descartados sem maiores consequências.

A escola entende esses corpos a partir de um vetor de inteligibilidade estável e excludente, ou seja, a heterossexualidade normativa (BUTLER, 2000). Além disso, a escola se posiciona no centro e coloca-os à margem. Esta também os determina e nomeia, com base no seu referencial, como "diferentes" (LOURO, 2004). Não os tolera. O que decorre disso é que o racismo gerado pela escola produz um efeito em que a exclusão se efetiva, em um nível elevado, na tentativa de garantir padrões 
de qualidade, ao formar as subjetividades desejadas pela pedagogia do controle. A partir de uma análise da biopolítica contemporânea, é possível pensar que na sociedade neoliberal, na qual as exigências de formação mínima para o exercício de qualquer atividade profissional intensificaram-se, os efeitos dessa tecnologia do poder empreendida pela escola são potencializados.

Atualmente, ser impedida(o) de estudar não representa apenas não estar na escola, mas denota não possuir valor na linha graduada das identidades modeladas pelo controle. Significa, ainda, não ter se esforçado o bastante, ser indolente e preguiçosa(o), não ter controle sobre si, nem saber planejar a vida e o futuro, obstaculizando o acesso aos bens e serviços da sociedade de controle para produzir a subjetividade desejada por ela. A exclusão implementada pela escola contemporânea é multifacetada e com implicações amplas sobre a vida dos sujeitos.

Esses sujeitos significam des/ordem, na "coerência" binária da escola. Talvez por colocarem em xeque o sistema corpo-sexo-gênero por meio da ambiguidade que revelam em relação às normas de gênero tão bem arquitetadas e naturalizadas nos espaços e tempos escolares. Para pensar sobre isso, é importante lembrar a organização dos espaços e das muitas atividades e até mesmo de disciplinas, como a Educação Física, por exemplo, que, normalmente, materializam as diferenças de forma binária e heteronormativa. As teorizações queer, assim como as experiências transexuais e travestis, desestabilizam e problematizam também a própria categoria de gênero.

O gênero, na ótica binária, foi edificado a partir da materialização dos dispositivos da sexualidade e da heterossexualidade por meio do dimorfismo sexual e de uma suposição naturalizada de sexo e de gênero (BUTLER, 2003). Pensar a partir da Teoria Queer denota romper radicalmente com o pensamento que gera e faz funcionar o sistema corpo-sexo-gênero, este, por sua vez, fundado no binarismo e situado na articulação do binômio normal-anormal.

O queer tem como pressuposição descentrar o centro, ou seja, questionar o lugar central de uma gama de características subjetivas como ser branco, homem, cristão, heterossexual (LOURO, 2004). O queer se aproxima do "ignóbil" e pensa a partir da diferença e da performatividade, comprovando a artificialidade da construção do gênero, do sexo e do corpo (BUTLER, 2003). A proximidade entre a Teoria Queer e a ambiguidade refere-se à própria consolidação dos sujeitos travestis e transexuais, uma vez que para muitos deles a ambiguidade significa a própria satisfação do desejo.

Essa dinâmica pode ser percebida nos sujeitos que produzem seus corpos e elegem seus nomes sociais como uma maneira de estar no mundo. No entanto, para além dos sujeitos e das classificações, queer é uma forma de pensar e de interpretar o mundo que pode ser estendida para a educação, suas instituições, seus discursos, normas e metodologias. Uma forma de pensar que permite rupturas e deslocamentos em relação aos pressupostos da escola, desafiando os dispositivos de controle. Nessa perspectiva, Louro (2004, p. 07-08, grifo do autor) diz que:

Queer é um jeito de pensar e de ser que não aspira o centro nem o quer como referência; um jeito de pensar e de ser que desafia as normas regulatórias da sociedade, que assume o desconforto da ambiguidade, do 'entre lugares', do indecidível. Queer é um corpo estranho, que incomoda, perturba, provoca e fascina.

Dessa forma, as teorizações queer problematizam a nova ordem pedagógica do controle em relação ao sistema corpo-sexo-gênero, admitindo uma fluidez em relação a esse sistema, não se preocupando em localizar-se no limite entre um sexo e outro, entre um gênero e outro, entre uma sexualidade e outra. Pensar queer incide no enfrentamento e na desestabilização da lógica binária. Um posicionamento queer frente à lógica estabelecida pela sociedade do controle permite adentrar a multiplicidade, entendendo como possíveis as várias formas do desejo e da fabricação de corpos e identidades, evidenciando também a artificialidade daquilo que compreende como "natural".

Esse posicionamento coloca em xeque também as respostas prontas que professoras(es), direção, equipe pedagógica e as/os novas(os) gestoras(es) da educação trazem arraigados consigo sobre currículos e práticas pedagógicas. Nos estudos de Louro (2004, p. 28-29): 
O grande desafio não é apenas assumir que as posições de gênero e sexuais se multiplicaram e, então, que é impossível lidar com elas apoiadas em esquemas binários; mas também admitir que as fronteiras vêm sendo constantemente atravessadas e - o que é ainda mais complicado - que o lugar social no qual alguns sujeitos vivem é exatamente a fronteira. Escolas, currículos, educadoras e educadores não conseguem se situar fora dessa história. Mostram-se, quase sempre, perplexos, desafiados por questões para as quais pareciam ter, até pouco tempo atrás, respostas seguras e estáveis. Agora, as certezas escapam, os modelos mostram-se inúteis, as fórmulas são inoperantes. Mas é impossível estancar as questões. Não há como ignorar as novas práticas, os novos sujeitos, suas contestações ao estabelecido. O anseio pelo cânone e pelas metas confiáveis é abalado. A tradição imediatista e prática leva a perguntar: o que fazer? A aparente urgência das questões não permite que se antecipe qualquer resposta; antes é preciso conhecer as condições que possibilitaram a emergência desses sujeitos e dessas práticas.

A escola contemporânea também pondera, objetiva e padroniza seus sujeitos através da sua genitália, no campo biológico. Para uma/um transexual ou travesti, uma atitude do dia a dia, como usar o banheiro da escola ou ser nomeada(o) por alguém, transforma-se em um problema.

Altmann e Martins (2007) analisam o discurso de uma diretora de escola sobre uma estudante travesti que desistiu da escola. Com vinte anos, a aluna foi matriculada pela mãe no Ensino Fundamental, na modalidade de Educação de Jovens e Adultos (EJA), no período noturno. Após efetivada a matrícula da aluna, a diretora a chamou para uma conversa sobre o uso do banheiro. A questão era: qual banheiro ela vai utilizar? Depois da conversa, mesmo a aluna dizendo que está acostumada a frequentar banheiros femininos, a diretora determinou que o banheiro que ela usaria seria o masculino, em razão de sua identidade civil e biológica. O motivo pelo qual essa decisão foi tomada consiste em, de acordo com a diretora, "não causar estranheza e constrangimento às senhoras que ali estudam" (ALTMANN; MARTINS, 2007, p. 134). Apesar da conversa entre diretora e aluna, o nome utilizado na escola também foi o civil, ou seja, o masculino. Dessa forma, para os/as autores(as):
Fisiologicamente, e perante a sociedade, ele é do sexo masculino, afirma a diretora. Vemos, nesse raciocínio, o biológico sendo colocado na origem da identidade de gênero. Podemos, no entanto, questionar se o órgão sexual masculino é mais definidor de sua identidade de gênero do que os seus desejos, sentimentos, jeito de se vestir, de se comportar etc. Vestir-se, comportar-se e sentir-se como mulher não seriam mais determinantes para a sua identidade do que os órgãos sexuais? Além disso, alguém vestida de saia, sapato de salto, maquiada, com bolsa e cabelo comprido produzirá mais constrangimento num banheiro feminino ou masculino? Todos esses símbolos de feminilidade estão muito mais visíveis do que um órgão sexual, que não precisa sequer ser visto por alguém, no uso do banheiro. Por fim, não poderia a escolha de Cristina ser o critério de definição do banheiro a ser frequentado? (ALTMANN; MARTINS, 2007, p. 135).

Mesmo com os Parâmetros Curriculares Nacionais (PCN), com o tratamento sobre Educação Sexual ou Educação para a sexualidade (como são denominadas) (BRASIL, 1997) e com os cursos de formação continuada para professoras(es), a presença de travestis e transexuais na escola inquieta, perturba e chega às vias do intolerável. Não parece ser uma experiência que consiga ser abrandada pelos ordenamentos da sociedade de controle. Do ponto de vista da Teoria Queer é uma experiência que, ao contrário, escapa e transgride. Esses corpos e identidades escapam do controle da instituição e da sociedade, isto é, travestis e transexuais, normalmente, não desejam ser incluídas(os), respeitadas(os) ou aceitas(os) se, para isso, tiverem que abdicar do que sentem e da forma como se identificam, fabricando corpos e identidades.

Louro (2004) afiança que a Teoria Queer tem a ver com uma disponibilidade para conhecer o que era impensável, argumentando sobre os entraves do conhecimento. Para ela, a possibilidade estaria abalizada sobre "[...] o que ou quanto um dado grupo suporta conhecer" (LOURO, 2004, p. 65). Esse assunto se torna essencial para pensar o impensável sobre a escola e a experiência transexual, pois convida a um mergulho no des/conhecido, a escapar da domesticação das alteridades geradas pela pedagogia do controle e a resistir e criar, pro- 
blematizando a docilidade e o governo a partir da compreensão da educação como um ato político de liberdade (CÉSAR, 2004). Conforme Gallo (2009, p. 31-32):

A liberdade é inerente à condição humana, mas nem sempre é exercitada. Para que sejamos livres de fato, é necessário que conquistemos e construamos a liberdade. E penso que a liberdade só é possível se todos são livres; não pode haver liberdade de uns, quando ela é condição de opressão de outros.

Dessa forma, vale pensar a educação como ação de resistência ao novo dispositivo do controle. Levando-se em consideração que as experiências aqui narradas erigiram alteridades a partir da sua fabricação voluntariosa e autêntica. Da mesma maneira, é importante compreender do contexto escolar - entendido como os acontecimentos cotidianos - as possibilidades e rotas de fuga em relação à nova ordem fixada pelo controle. Ainda de acordo com Gallo (2009, p. 38-39):

Abrir-se para as relações do cotidiano da escola, mergulhar nesses acontecimentos, agindo como vetor de transformação é possibilidade de resistir à exclusão e investir na construção da cidadania. [...] Para resistir é importante abrir-se ao acontecimento. Estar atento àquilo que ocorre no cotidiano da escola, a fim de potencializá-lo criativamente, e não ser tragado engolido pelo acontecimento. Perder-se no acontecimento, não conseguindo produzir, é tão ruim quanto estratificá-lo, fazê-lo perder a potência, dominando os fluxos e reenquadrando as diferenças na norma. Resistir e criar. Essas são as possibilidades que nos abre o cotidiano da escola, quando escolhemos agir no fluxo dos acontecimentos.

Uma reflexão queer para combater e criar diante das situações do cotidiano escolar parece ser crível por meio da articulação entre escola e a multifacetada experiência transexual. Essa aproximação, pautada pelo questionamento e pela pluralização, pode produzir um deslocamento nas formas de pensar as sexualidades engendradas pelos discursos e por meio de práticas. Considerando com isso as alternativas e arranjos do desejo, será possível a geração de pedagogias que produzam "menos discursos normalizadores dos corpos, dos gêneros, das relações sociais, da afetividade e do amor" (BRITZMAN, 1996, p. 93).

\section{Regulamentação do nome social de estudantes travestis e transexuais no Brasil}

No campo da legislação, várias leis foram produzidas para garantir o acesso e a permanência de todos os sujeitos na escola, sejam índios(as), negros(as), pessoas com necessidades especiais, idosos(as) e LGBT (lésbicas, gays, bissexuais, travestis e transexuais). Dessa forma, as leis vêm legitimar a Constituição Federal de 1988 no Artigo 3, que apregoa: "Promover o bem de todos, sem preconceitos de origem, raça, sexo, cor, idade, ou quaisquer outras formas de discriminação" e ainda no Artigo $5^{\circ}$, quando afirma que "todos são iguais perante a lei, sem distinção de qualquer natureza [...]" (BRASIL, 1988).

As relações de gênero transcorrem todas as interações no cotidiano escolar, mas são pouco debatidas enquanto relações de poder e hierarquia entre homens e mulheres. Os direitos educacionais dos sujeitos LGBT em alguns estados, como no caso de Paraná, São Paulo, Pará, dentre outros, têm sido garantidos através de legislações que proíbem a discriminação e o preconceito, instituem um calendário de ações como o dia de combate à homofobia (18 de maio), uma vez que a escola pode acabar por criar ou potencializar conceitos sociais já construídos nos(as) alunos(as), pois, como afiança Furlani (2008, p. 07), "os gêneros e as sexualidades são constantemente produzidos e, se poderia dizer ensinados por meio de representações", ou seja, papéis são socialmente e historicamente construídos e ensinados para o sexo macho, diferentes dos ensinados/construídos para o sexo fêmea.

Boa parte dos discursos e concepções identitárias de travestis e transexuais gira em torno da adequação do nome à sua expressão/identidade psíquica e social de gênero. $\mathrm{O}$ emprego do nome adequado às subjetividades emocionais e psicológicas da pessoa pode ser feito de forma independente - a partir de como ela se identifica e é reconhecida socialmente - ou com base em dispositivos jurídicos que garantem e autorizam tal adaptação, como o uso do nome social e a retificação de registro civil (ou mudança de prenome).

O nome social é aquele pelo qual sujeitos autodenominados travestis ou transexuais optam por ser 
chamados cotidianamente, refletindo sua expressão de gênero, em detrimento ao seu nome de registro civil, dado em consonância com o gênero e/ou o sexo atribuídos durante a gestação e/ou nascimento.

A utilização do nome social tem sido regularizada por entidades como o Conselho Regional de Medicina do Estado de São Paulo (CREMESP) e o Ministério da Educação (MEC), dentre outros órgãos normativos, sobretudo os ligados às áreas da saúde e educação. O CREMESP, através da Resolução n ${ }^{\circ} 208$, de 27 de outubro de 2009, assegura, em seu artigo $2^{\circ}$, "o direito de usar o nome social, podendo os/as paciente indicar o nome pelo qual preferem ser chamados/as, independente do nome que consta no seu registro civil ou nos prontuários do serviço de saúde.” (SÃO PAULO, 2009).

No entanto, a maioria das resoluções parte de órgãos relacionados ao MEC. Por exemplo, a Portaria $n^{\circ}$ 016/2008 - GS, de 10 de abril de 2008, fls. 23, da Secretaria de Educação do Pará, estabelece em seu artigo $1^{\circ}$ que, "a partir de 02 de janeiro de 2009, todas as Unidades Escolares da Rede Pública Estadual do Pará passarão a registrar, no ato da matrícula dos alunos, o pré-nome social de Travestis e Transexuais." (PARÁ, 2008).

Em 03 de abril de 2009, a Resolução CEE/CP n ${ }^{\circ}$ 5, fl. 19, do Conselho Estadual de Educação (CEE) de Goiás, dispôs sobre "a inclusão do nome social de travestis e transexuais nos registros", enfatizando o objetivo de "garantir o acesso, a permanência e o êxito desses cidadãos no processo de escolarização e de aprendizagem nos documentos escolares internos", tendo a/o estudante travesti ou transexual que "manifestar, por escrito, seu interesse da inclusão do nome social no ato de sua matrícula ou ao longo do ano letivo" (GOIÁS, 2009a). O mesmo Conselho, na mesma data, publicou o Parecer $n^{\circ}$ 04/2009, de 03 de abril de 2009, fls. 20 a 22, determinando que "as escolas do sistema educativo de Goiás, em respeito à diversidade, à dignidade humana e à inclusão social, incluam o nome social de travestis e transexuais", a partir da "manifestação por escrito do interessado, que deverá acompanhar seu dossiê escolar, ficando excluídos o diploma e o histórico escolar." (GOIÁS, 2009b).

Em junho de 2011, um decreto foi publicizado pelo Diário Oficial, prescrevendo o tratamento nominal, inclusão e uso do nome social de travestis e transexuais em órgãos públicos estaduais, situando nome social como aquele pelo qual travestis e transexuais se identificam mediante a sociedade. Com base no Decreto $\mathrm{n}^{\circ} 22.331$, de 13 de agosto de 2011, emitido pelo Diário Oficial do Estado do Rio Grande do Norte e assinado pela então governadora Rosalba Ciarlini, os órgãos públicos desse Estado passam a aceitar o uso de nome social de transexuais e travestis (RIO GRANDE DO NORTE, 2011). O CEE do Espírito Santo deliberou, em 2011, resolução que admite a inclusão do nome social de travestis e transexuais nos diários escolares da rede estadual de ensino. O nome social é colocado entre parênteses, após o nome de registro do aluno.

A Portaria $n^{\circ} 1.612$ do Ministério da Educação, de 18 de novembro de 2011, assinada pelo então ministro Fernando Haddad e emitida pelo Diário Oficial da União ${ }^{\circ} 222$, de 21 de novembro de 2011, garante "o direito à escolha de tratamento nominal nos atos e procedimentos promovidos no âmbito do Ministério da Educação.", entendendo por nome social "aquele pelo qual essas pessoas se identificam e são identificadas pela sociedade.” (BRASIL, 2011, p. 67), assegurando o uso do nome social conforme requerimento da pessoa interessada.

No que se refere à utilização do nome social por travestis e transexuais, as tensões abrangem essas pessoas e outros sujeitos e/ou instâncias que muitas vezes procuram regulamentar seus direitos e classificar suas identidades, como a esfera pública e movimentos sociais LGBT, advogados(as), juízes(as), médicos(as), líderes religiosos, profissionais da área "psi" (psicólogos, psicanalistas, psiquiatras etc.), acadêmicos(as), mídia, caracterizadas(os), não raro, por seu caráter autoritário.

Em 2014, a pesquisadora Ariana Sala ${ }^{2}$ realizou um levantamento sobre a escolarização de travestis e transexuais nas instituições escolares brasileiras (SALA, 2014). A seguir, reproduzo um mapa da referida pesquisadora sinalizando os Estados que já aprovaram legislação a favor do uso do nome social de estudantes travestis e transexuais, bem como um quadro que atualiza, em outubro de 2015, seu dados.

\footnotetext{
2 Atendendo ao Edital 055/2014 da OEI, a pesquisadora Ariana Sala (2014) redigiu um documento técnico contendo diagnóstico da situação educacional de travestis e transexuais, apontando possibilidades de ações articuladas junto a programas do Ministério da Educação e aos sistemas de ensino voltados à formação básica, profissional e superior.
} 
Figura 1 - Disseminação do uso do nome social nas Instituições Públicas de Ensino Superior e regulamentações formuladas por Secretarias ou Conselhos Estaduais de Educação

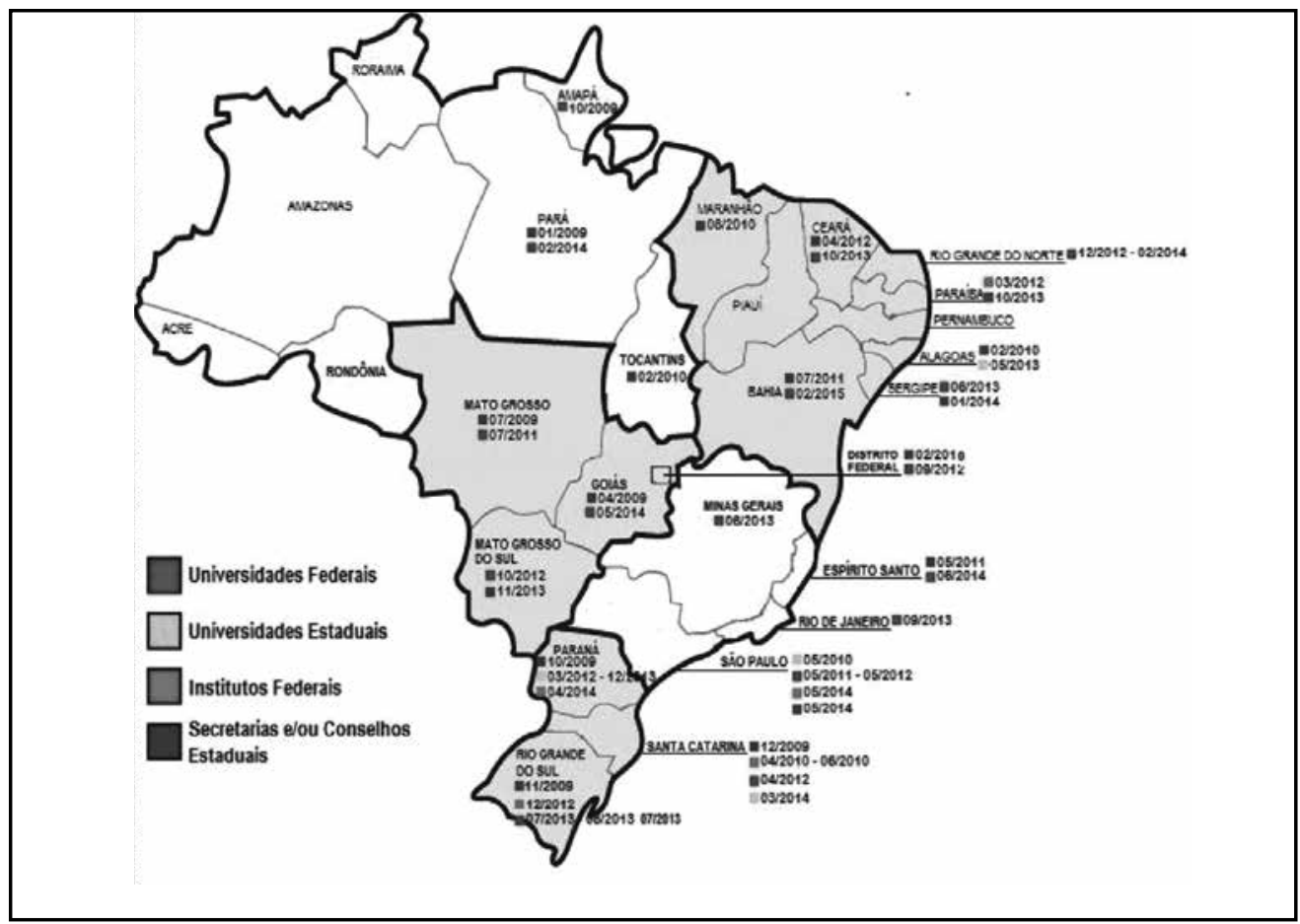

Fonte: Sala (2014, p. 20).

Quadro 1 - Disseminação do uso do nome social nas Instituições Públicas de Ensino Superior e regulamentações formuladas por Secretarias ou Conselhos Estaduais de Educação - atualização realizada em outubro de 2015

\begin{tabular}{|l|l|c|}
\hline \multicolumn{1}{|c|}{ ÓRGÃO/ INSTITUIÇÃO } & \multicolumn{1}{|c|}{ REGULAMENTAÇÃO } & DATA \\
\hline $\begin{array}{l}\text { Universidade Federal Rural do Rio } \\
\text { de Janeiro }\end{array}$ & $\begin{array}{l}\text { Deliberação no 43, de 29 de julho de 2014. (RIO DE } \\
\text { JANEIRO, 2014). }\end{array}$ & $07 / 2014$ \\
\hline $\begin{array}{l}\text { Prefeitura Municipal de Vitória da } \\
\text { Conquista-BA }\end{array}$ & $\begin{array}{l}\text { Decreto } \text { n }^{\circ} \text { 14.273 (Dispõe sobre a possibilidade de } \\
\text { travestis e transexuais usar o nome pelo qual querem } \\
\text { ser reconhecidas, nos órgãos da Administração Pública } \\
\text { Municipal direta e indireta, autarquias, fundações e nas } \\
\text { instituições públicas municipais de ensino) (VITÓRIA } \\
\text { DA CONQUISTA, 2012). }\end{array}$ & $02 / 2012$ \\
\hline $\begin{array}{l}\text { Secretaria Municipal de Educação } \\
\text { de Fortaleza-CE }\end{array}$ & $\begin{array}{l}\text { Portaria 03/2010 (Regulamenta o uso do nome social de } \\
\text { estudantes travestis e transexuais na Rede Municipal de } \\
\text { Ensino de Fortaleza) (FORTALEZA, 2010). }\end{array}$ & $03 / 2010$ \\
\hline
\end{tabular}




\begin{tabular}{|c|c|c|}
\hline Prefeitura Municipal de Vitória-ES & $\begin{array}{l}\text { Lei } \mathrm{n}^{\circ} 8.585 \text { (Dispõe sobre os parâmetros para inclusão } \\
\text { do nome Social de Travestis e Transexuais nos registros } \\
\text { escolares das escolas do sistema municipal de Ensino de } \\
\text { Vitória - ES) (VITÓRIA, 2013). }\end{array}$ & $12 / 2013$ \\
\hline $\begin{array}{l}\text { Conselho Municipal de Educação } \\
\text { de Belo Horizonte -MG }\end{array}$ & $\begin{array}{l}\text { Resolução CME/BH n }{ }^{\circ} \text { 002/2008 (Dispõe sobre os } \\
\text { parâmetros para a Inclusão do Nome Social de Travestis } \\
\text { e Transexuais nos Registros Escolares das Escolas da } \\
\text { Rede Municipal de Educação de Belo Horizonte - RME/ } \\
\text { BH) (BELO HORIZONTE, 2008). }\end{array}$ & $12 / 2008$ \\
\hline Prefeitura Municipal de Canoas-RS & $\begin{array}{l}\text { Decreto } n^{\circ} 37 \text { (Dispõe sobre o tratamento nominal, } \\
\text { inclusão e uso do nome social de travestis e transexuais } \\
\text { nos registros municipais relativos aos serviços públicos } \\
\text { prestados no âmbito do Poder Executivo municipal e dá } \\
\text { providências) (CANOAS, 2015). }\end{array}$ & $01 / 2015$ \\
\hline $\begin{array}{l}\text { Secretaria Municipal de Educação } \\
\text { de Campinas-SP }\end{array}$ & $\begin{array}{l}\text { Resolução SME/FUMEC no 04/2015 (Dispõe sobre o } \\
\text { tratamento nominal de alunos transexuais e travestis, no } \\
\text { âmbito do Sistema Municipal de Ensino de Campinas) } \\
\text { (CAMPINAS, 2015). }\end{array}$ & $02 / 2015$ \\
\hline $\begin{array}{l}\text { Conselho Nacional de Combate à } \\
\text { Discriminação de LGBT }\end{array}$ & $\begin{array}{l}\text { Resolução CNCD/LGBT no } 12 \text { (Estabelece parâmetros } \\
\text { para a garantia das condições de acesso e permanência } \\
\text { de pessoas travestis e transexuais - e todas aquelas que } \\
\text { tenham sua identidade de gênero não reconhecida em } \\
\text { diferentes espaços sociais - nos sistemas e instituições } \\
\text { de ensino, formulando orientações quanto ao } \\
\text { reconhecimento institucional da identidade de gênero e } \\
\text { sua operacionalização) (BRASIL, 2015). }\end{array}$ & $01 / 2015$ \\
\hline
\end{tabular}

Fonte: Elaborado pelo autor deste artigo.

\section{Para além da legislação: travestis e transexuais nas relações escolares}

A diversidade sexual e de gênero surge no campo político e teórico enquanto matéria imprescindível para análise, na medida em que processos excludentes são particularmente vivenciados por lésbicas, gays, bissexuais, travestis e transexuais (LGBT) em relações sociais que continuamente reafirmam a discriminação e o preconceito fundamentados na heterossexualidade como referência normativa e nos padrões binários de gênero. No interior dessa composição, cabe ressaltar o conjunto que compreende, de forma mais específica, a experiência social de travestis e transexuais. Esses sujeitos, como todos os integrantes da população LGBT, estão vulneráveis a multíplices processos cotidianos de agressão e de estigmatização; todavia, comparativamente aos demais indivíduos que compreendem o dito grupo, são frequentemente relegados ao esquecimento no que se refere a políticas públicas educacionais.

Entender a experiência social de travestis e transexuais demanda um olhar cuidadoso às condições materiais operacionalizadas por esses sujeitos para viver, bem como aos modos culturais como vivem (MARTINELLI, 1999), esquadrinhando, nesse ínterim, as situações violentas que possam constituir 
a aludida experiência. Se é verdade que as subjetividades travestis e transexuais são perpassadas pela ocorrência de brutalidades - que podem ser físicas, morais, psicológicas e mesmo simbólicas -, considera-se imprescindível focalizar a atenção quanto ao que se refere à recusa da plena identidade de gênero, parte integrante do direito à personalidade e, portanto, condição inerente à dignidade da pessoa humana (BRASIL, 2015).

O documentário “Ser Mulher" (SER..., 2007) apresenta as falas de quatro mulheres transexuais que assumiram ter tido problemas com o preconceito e a discriminação na época escolar:

Depois de 20 anos fora da escola por medo, né, do preconceito, da discriminação, parei de estudar, e 20 anos depois eu resolvi voltar. No primeiro dia de aula eu não queria ir. Eu tive dor de barriga, eu tive cólica, eu tive vontade de chorar, eu não queria ir. (CARLA, 34 ANOS, CURITIBA).

Pode-se notar o aparecimento de um sentimento de horror ao ambiente escolar vivenciado por Carla. No mesmo sentido, três dos quatro homens transexuais que integram o documentário "Sou Homem" (SOU..., 2008) narram suas histórias de vida, marcadas por experiências desagradáveis e traumatizantes na escola:

[...] eu não queria colocar calcinha, nada disso, eu queria colocar um tênis, chegar na hora do recreio e jogar futebol com a molecada, aí eles pensavam: 'aquela ali é Maria-homem!' Maria-homem por quê? Não pela minha fisionomia, mas por causa do nome. Aí a professora vinha e falava: 'Você não vai falar 'presente'?' E eu falava: 'Mas a senhora não falou meu nome!' Ela falava: 'Falei sim, falei seu nome!' E eu dizia: 'Esse não é meu nome!' E ela disse: ‘É sim!' E eu falava: 'Então eu não vou responder!' Aí, eu ficava calado. Então, ela sabia que era eu e não perguntava mais, porque ela via que eu estava lá. (CELINHO, SÃO PAULO).

Tive um fato na minha vida que me marcou muito. Eu tinha quatro amigos na escola e, assim... a gente sempre tava jogando bola na quadra da escola, tudo, e eu usava o banheiro masculino. E um dia quando eu entrei no banheiro masculino, não sei se os caras tinham bebido ou usado algum tipo de droga, e eles tiveram uma reação complicada comigo e eu acabei sendo estuprado pelos quatro. [...] Hoje, depois dos trinta anos eu contei para alguém. Eu acho ainda complicado voltar para a escola, eu sei que eu tenho que terminar meus estudos, mas eu não consigo entrar numa escola, eu me sinto em um lugar que eu não tenho saída, quando eu estou dentro de uma escola. (XANDE, SÃO PAULO).

Esses discursos são reiterados pela declaração de Diwa Santos, 20 anos, que desistiu da escola na $6^{\text {a }}$ série por não suportar o assédio dos colegas e até de alguns(mas) educadores(as), optando por interromper os estudos. Diz ela: "Sofri mais pressão da sociedade e do colégio do que dos familiares." Conforme o jornal, "Até hoje ela lembra, com constrangimento, dos episódios que a levaram a abandonar o colégio, entre eles o de ter o nome de homem na lista de chamada." (TRANSEXUAL..., 2009).

A problemática explicitada nessas experiências que transgridem as rígidas e quase intransponíveis normas de gênero fortalece o nome como uma questão relevante, bem como a sua representação para sujeitos transexuais e travestis. O nome social foi o nome eleito, muitas vezes, pelo sujeito e outras tantas por uma/um transexual ou travesti mais velha(o), que desempenha a função de guia, também cognominada de madrinha ou mãe. O significado desse nome é estabelecido juntamente com a identidade de gênero produzida pelas(os) transexuais e travestis como uma espécie de legenda, isto é, uma identificação diante do mundo e, sobretudo, materializa a nova identidade fabricada pela construção do corpo. Para grande parte das(os) travestis e transexuais, a utilização do nome social em detrimento do nome civil parece propiciar uma sensação de conforto e satisfação. Parece ainda garantir, de alguma maneira, o reconhecimento de outros sujeitos sobre seus processos de fabricação, tanto naquilo que remete a seus corpos, como também às suas identidades. Essa peleja por uma legitimação de compreensão, por parte da sociedade, dos processos de fabricação pode ser entendida a partir do referencial das ordens de inteligibilidade dos gêneros, como a arquitetada por Butler (2003, 2006).

O nome propicia basicamente o reconhecimento de uma pessoa e assinala imediatamente uma identidade de gênero. Nessa visão, nomes com significado ambíguo normalmente geram um certo constrangimento da perspectiva do outro. Por 
exemplo, ao ouvirmos um nome como Valdeci, logo buscamos saber se se trata de uma mulher ou de um homem. Na perspectiva das políticas das diferenças, as relações se complexificam no campo da escola. O nome impulsiona também meios de classificar, categorizar, agrupar por semelhanças, opor e comparar grupos pelas diferenças. A ação de designar uma/um transexual ou travesti pelo seu nome civil desperta sentimentos de dor, raiva, angústia e revolta.

Na obra $A$ reinvenção do corpo, Bento (2006) recolhe vários depoimentos de mulheres e homens transexuais que reafirmam a exclusão escolar fruto de preconceito e discriminação:

Kátia: Na escola, quando me chamavam de veado ou de macho-fêmea, eu chorava, me afastava de todo mundo, não saía para o recreio. Eu só tenho a $3^{\text {a }}$ série completa. Eu parei em $96 .$. Eu parei de estudar no meio da $4^{\mathrm{a}}$ série. Notas boas... por causa desse preconceito que não aguentava. Não aguentei o preconceito de me chamarem de macho-fêmea, de veado, de travesti, essas coisas todas.

Pedro: Agora eu estou tentando voltar a estudar. Quando eu era pequeno, todo dia eu voltava para casa todo machucado. Me chamavam de macho-fêmea, sapatão. Eu não aceitava. A diretora chamava minha mãe. Era uma confusão. Até que um dia eu parei de ir. (BENTO, 2006, p. 130).

Esses sujeitos e seus respectivos discursos têm algo a narrar à organização da escola pública? Como esses depoimentos interagem com as relações sociais na escola? Por que essas narrativas podem ser compreendidas como enredo das condutas normativas da escola? Transexuais são sujeitos que subvertem as inflexíveis normas de gênero e sexualidade vigentes na sociedade contemporânea e, ao transgredirem as expectativas em relação ao sistema sexo/gênero, podem provocar um diálogo para uma pedagogia queer. Queer para que possamos viver em um mundo não fascista (FOUCAULT, 2008). Para que tantos sujeitos não sejam mortos por conta de sua orientação sexual ou pelo seu corpo transformado; para que não haja a destruição, a violência, o castigo, a evasão contra quem transgride as regras da heterossexualidade compulsória, ou heteronormatividade, e para que todas(os) possamos romper os limites do pensamento e do des/conhecimento.
Por que a escola e as práticas escolares? Porque a escola se constituiu na história institucional como um espaço de segregação por ser uma instância destinada à fabricação e reprodução da norma em todas as esferas e relações, e nas primeiras décadas do século XX no Brasil já produzia uma educação sexual normalizadora, higienista e eugenista (VIDAL, 2002).

Os discursos mencionados e sua investigação denotam aspectos extremamente transfóbicos e práticas escolares excludentes e perversas em relação aos sujeitos transexuais. São os instrumentos do dispositivo da sexualidade explicitados por Foucault (1984) na sua História da Sexualidade - Vontade de Saber em pleno funcionamento. De acordo com o filósofo, dispositivos "são formados por um conjunto heterogêneo de práticas discursivas e não discursivas que possuem uma função estratégica de dominação. O poder disciplinar obtém sua eficácia da associação entre os discursos teóricos e as práticas reguladoras." (FOUCAULT, 1984, p. 244).

Conforme Butler (2003), para que a ordem do mundo seja restaurada, ordem esta que se configura dentro de uma estrutura binária, disjuntiva e dessimétrica do feminino/masculino, o gênero que se apresenta ininteligível, numa compreensão primária das relações, precisa ser extinto, dada a incapacidade de compreendê-lo. Para Butler (2003, p 57), “[...] essas configurações culturais de confusão de gênero atuam como ambientes de intervenção, denúncia e deslocamento das reificações. Em outras palavras, a unidade do gênero por via da heterossexualidade compulsória".

Diante do explicitado, uma das interpretações possíveis é que o emprego do nome civil em oposição do nome social na escola é uma das táticas do dispositivo da sexualidade de Foucault articulada à heteronormatividade de Butler imbricada na teia de práticas escolares que expelem sujeitos e determinam lugares aos quais transexuais e travestis podem pertencer ou nem sequer podem desejar pertencer.

\section{Considerações finais}

Há particularidades no universo de travestis e transexuais próprias de seus estilos de vida que se traduzem no jeito de ser e estar no mundo. Essas possibilidades existenciais, que denotam toda a 
disposição de suas subjetividades, são geradas por meio das relações que o sujeito institui com a família, com a comunidade, com a escola, com o trabalho, com os/as amigos(as) e nas relações afetivas e sexuais. É uma configuração própria de linguagens, comportamentos, regras de aceitabilidade e de modificação corporal. De acordo com Peres (2004), o diálogo do masculino e do feminino no mesmo corpo nos leva a interrogar a respeito das classificações de gênero tradicionais que binarizam e polarizam condutas, posturas e comportamentos. Mediante esse panorama de oposições binárias entre a heterossexualidade e a homossexualidade, entre o normal e o patológico que amainam a vida e fazem dela uma normatização opaca e enrijecida, uma possível saída talvez esteja na flexibilização dos conhecimentos e dos poderes de forma a conduzir nossa atenção para as diferenças, o efêmero, o abjeto, e a gerar mais inclusão e cooperação.

Contra a denominada "pedagogia do insulto" (SULLIVAN, 1996) - um relevante mecanismo de negação e de dominação simbólica - não existe fórmula, nem um singular padrão de enfrentamento na educação, na saúde ou nas demais áreas. Talvez somente a "lucidez profissional" (PERRENOUD, 2007) como modo de competência básica pode reafirmar a proibição das violências e da exclusão.

É possível acreditar no potencial realizador dos(as) educadores(as) para a edificação de uma sociedade capaz de garantir direitos sociais, políticos, econômicos e culturais para todos os sujeitos, e na segurança de que as diferenças de classe, raça, etnia, etárias, de gênero e de orientação sexual não exprimam processos de legitimação de hierarquias sociais e de exclusão, mas que, contudo, o preconceito e a discriminação estejam ausentes entre os sujeitos que compõem o ambiente educacional. Somente duas décadas depois de ratificada a Constituição Federal de 1988 é que o poder público começa a debater e a construir com os sujeitos LGBT políticas públicas capazes de afiançar, ou tentar afiançar o cumprimento de alguns direitos que já estavam assegurados na Carta Magna, porém esquecidos.

Dessa forma, mecanismos legais foram produzidos em níveis nacional, estadual e municipal, com o intuito de assegurar o acesso e a permanência de todos os "sujeitos da diversidade" na educação pública e gratuita. Políticas públicas em Educação apenas asseguram a aplicabilidade das ações se os/ as atores da educação compreenderem o processo, a necessidade de respeitar as diferenças e apoiar a inclusão, já que é necessário provocar reflexões críticas entre os/as profissionais da educação sobre a construção dicotômica de gênero em nossa sociedade na severa demarcação dos papéis masculinos e femininos possíveis de gerar discriminações e preconceitos. Ainda que existam políticas que expandam os direitos dos sujeitos da diversidade, a escola somente se transformará em um espaço de inclusão da diversidade se propiciar o debate, a investigação das relações sociais e da transformação do sujeito, por meio de uma educação sexual fundamentada nas relações humanas. Para isso, faz-se imprescindível programas de formação inicial e continuada de professores que contemplem a temática da diversidade sexual. A essa demanda inclui-se a revisão e reorganização curricular dos cursos de licenciatura, de modo que na graduação a temática já possa ser debatida e refletida entre os/ as futuros(as) professores(as).

Por fim, faz-se relevante ponderar sobre a implicação da desconstrução e problematização da matriz heteronormativa que a presença de alunos(as) travestis e transexuais pode proporcionar na instituição escolar. $\mathrm{O}$ nome social tem algo a dizer de suas experiências identitárias e de gênero; logo, a legitimação dele nos registros escolares ajuda na socialização deles(as) no universo escolar. No entanto, o poder público, especialmente o municipal e estadual, também necessita investir em ações paralelas como divulgação das políticas, dos programas e dos equipamentos públicos de subsídio e de direitos à população LGBT; alargamento do debate do currículo escolar, incluindo a diversidade sexual; e supervisão constante das práticas pedagógicas. Tais ações objetivam assegurar a participação desse segmento nos processos de identificação, socialização e aprendizagem presentes na escola, além de concretizar o direito ao acesso, à permanência e continuidade da escolarização, através de condições equitativas de aprendizagem, na direção da universalização da Educação Básica.

A regulamentação do uso do nome social na escola, ainda que bem intencionada, não conseguiu, pelo menos até o momento, mobilizar a esperada 
"educação inclusiva" para travestis e transexuais, pois a legitimação do uso do nome social não foi acompanhada de outros investimentos necessários. Isso porque a homofobia e a transfobia configuram-se em um dos principais fatores vivenciados no cotidiano escolar que inviabilizam o sucesso da regulamentação do nome social como estratégia de inclusão. A homo/transfobia que perpassa os diversos âmbitos escolares provoca a sensação de que a escola não é lugar para travestis e transexuais, com base no não respeito ao nome social, na proibição do uso do banheiro que corresponda ao gênero identificado, no não reconhecimento da travestilidade e da transexualidade como formas possíveis de estar no mundo. Além disso, a regulamentação do nome social é pouco conhecida entre professores(as), diretores(as) e até mesmo pelos sujeitos transexuais e travestis.

A partir de 2003, as políticas de educação inclusiva são alavancadas no Brasil com projetos que preveem a inclusão não apenas de sujeitos com deficiência, mas de todas as pessoas que sofrem alguma forma de exclusão educacional. No entanto, a inclusão continua sendo um dos temas mais controversos na educação atual. Há leis (Constituição de 1988, Lei de Diretrizes e Bases para a Educação Nacional de 1996 etc.), declarações internacionais (Declaração de Mundial sobre Educação para Todos, de 1990, Declaração de Salamanca, de 1994 etc.) e regulamentações diversas (Plano Nacional de Educação, Parâmetros Curriculares Nacionais, Plano Nacional de Direitos Humanos etc.) sobre educação inclusiva, mas é visível que a escola ainda não dá conta de acolher a diversidade de formas de viver.

A heterossexualidade permanece como parâmetro em relação a qual as outras formas de viver são comparadas. É a condição de vida desejável, normal, logo, todas as demais são vistas de modo negativo. Se, como dito anteriormente, a regulamentação do nome social não conseguiu produzir a inclusão de travestis e transexuais, ao menos provoca alguma tensão no regime de verdade que nega aos sujeitos trans o direito ao nome e à escola.

A regulamentação do nome social provocou diversos efeitos de subjetivação, produzindo processos de capturas identitárias, concomitante ao ensaio de possibilidades de resistência. Tais capturas se referem aos processos que vinculam o acesso ao direito a uma identidade preestabelecida, ou seja, é preciso "se assumir" como travesti ou transexual para poder usar o nome social no ambiente escolar. O problema em tal adesão identitária reside nas tecnologias de controle que a ela são atreladas.

Assim, a autorização de usar o nome social remete à luta pelo direito às diferenças, de efetivar os modos de viver que o sujeito considera adequado. De algum modo, há o reconhecimento de experiências diferentes da heterossexualidade. Há também o reconhecimento de que travestis e transexuais sofrem uma série de constrangimentos no cotidiano escolar por terem uma aparência incompatível com o nome do registro civil. Por isso, para tentar minimizar a "evasão escolar" dessa população, geraram-se as legislações aqui apresentadas.

Ao serem considerados(as) “diferentes”, travestis e transexuais apenas confirmam a norma identitária que tem no homem branco, de bom poder aquisitivo, ocidental, cristão e heterossexual seu vetor de referência. Dessa forma, a diferença também é tida como negativo do idêntico, pois não se trata de uma mera diferença, mas de uma diferença desigual, produzida no interior de relações de poder por dispositivos biopolíticos. Para o senso comum, travestis e transexuais não são apenas diferentes, são inferiores e, por isso, necessitam de políticas para que retornem ou permaneçam na escola.

Por isso, professores(as), diretores(as), psicólogos(as), assistentes sociais, funcionários(as) de diversos setores da educação poderiam formar uma frente de luta para as questões que envolvam diversidade sexual. Seria o começo para uma mobilização por práticas transformadoras e por reflexões críticas sobre a presença da diversidade de formas de viver na escola.

A normatização do nome social, mesmo com boas intenções, acaba sendo partícipe de uma inclusão incompleta. A falta de implementação, acompanhamento e informação da portaria nas escolas, sem dúvida, são elementos a serem considerados. Assim como as condições precárias de vida que grande parte de travestis e transexuais são submetidas, que inviabilizam o retorno ou permanência dessa população na escola. Nesse sentido, a atuação dos movimentos sociais LGBT são imprescindíveis 
para que, de fato, a regulamentação seja efetivada, bem como outras políticas de inclusão de sujeitos trans sejam alavancadas no sistema educacional. O que obrigaria a caminhar na contramão dessa inclusão incompleta, de modo a forçar uma inclusão nos limites do possível. Não há modelos a seguir, mas há possibilidades a serem criadas. Inclusão como atitude crítica, que possibilite problematizar as formas de ser governado(a) e as de não ser governado(a). Uma nova forma de inclusão que opere a partir da resistência ao rotineiro, previsível, invisível e ordinário.

\section{REFERÊNCIAS}

ALTMANN, Helena; MARTINS, José Carlos. Políticas da sexualidade no cotidiano escolar. In: CAMARGO, Ana Maria Facciolli; MARIGUELA, Márcio (Org.). Cotidiano escolar: emergência e invenção. Piracicaba, SP: Jacintha, 2007. p. 128-142.

BELO HORIZONTE. Conselho Municipal de Educação. Resolução CME/BH n⿳0 002/2008, de 23 de julho de 2009. Dispõe sobre os parâmetros para a inclusão do nome social de travestis e transexuais nos registros escolares das escolas da rede municipal de educação de Belo Horizonte-RME/BH. Belo Horizonte, 2008. Disponível em: $<$ http://portalpbh.pbh.gov.br/pbh/ecp/comunidade.do?evento=portlet\&pIdPlc=ecpTaxonomiaMenuPortal\&app=c me\&lang=pt_BR\&pg=8002\&tax=20660>. Acesso em: 05 out. 2015.

BENTO, Berenice Alves de Melo. A (re)invenção do corpo: sexualidade e gênero na experiência transexual. Rio de Janeiro: Garamond/CLAM, 2006.

BRASIL. Ministério da Educação. Portaria no 1.611, de 17 de novembro de 2011. Brasília, DF, 2011. Disponível em: $<$ http://www.in.gov.br/visualiza/index.jsp?data=21/11/2011\&jornal=1\&pagina=68\&totalArquivos=168>. Acesso em: 05 out. 2015.

. Presidência da República. Constituição da República Federativa do Brasil de 1988. Disponível em:

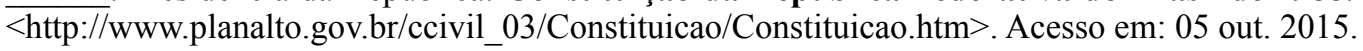

. Secretaria de Educação Fundamental. Parâmetros Curriculares Nacionais. Orientação sexual. Brasília: $\overline{\mathrm{MEC} / \mathrm{SEF}}$ 1997. Disponível em: <http://portal.mec.gov.br/seb/arquivos/pdf/orientacao.pdf>. Acesso em: 05 out. 2015.

Câmara dos Deputados. Lei de Diretrizes e Bases da Educação Nacional. Série Separata de Leis, Decretos, etc. n. 11/96. Centro de Documentação e Informação. Brasília, DF, 1996.

Secretaria de Direitos Humanos da Presidência da República. Conselho Nacional de Combate à Discriminação de LGBT. Resolução CNCD/LGBT no $\mathbf{1 2}$ /2015, de 16 de janeiro de 2015. Estabelece parâmetros para a garantia das condições de acesso e permanência de pessoas travestis e transexuais - e todas aquelas que tenham sua identidade de gênero não reconhecida em diferentes espaços sociais - nos sistemas e instituições de ensino, formulando orientações quanto ao reconhecimento institucional da identidade de gênero e sua operacionalização. Brasília, DF, 2015. Disponível em: <http://www.semesp.org.br/semesp_beta/wp-content/uploads/2015/03/ COMUNICADO-JURIDICO-Resolu\%C3\%A7\%C3\%A3o-LGBT-n\%C2\%BA-12.pdf $>$. Acesso em: 05 out. 2015.

BRITZMAN, D. O que é esta coisa chamada amor: identidade homossexual, educação e currículo. Educação \& Realidade, v. 1, n. 1, p. 71-96, fev. 1996.

BUTLER, J. Problemas de gênero: feminismo e subversão da identidade. 3. ed. Rio de Janeiro: Civilização Brasileira, 2003.

. Corpos que pesam: sobre os limites discursivos do "sexo". In:

$\overline{\text { gias da }}$ sexualidade. 2. ed. Belo Horizonte: Autêntica, 2000. p. 151-172.

(Org.). O corpo educado: pedago-

Deshacer el gênero. Barcelona: Paidós, 2006.

CAMPINAS. Secretaria Municipal de Educação de Campinas. Resolução SME/FUMEC nº4/2015, de 30 de março de 2015. Dispõe sobre o tratamento nominal de alunos transexuais e travestis, no âmbito do Sistema Municipal de Ensino de Campinas. Campinas, SP, 2015. Disponível em: <http://www.jusbrasil.com.br/diarios/89506527/ dom-camp-31-03-2015-pg-10>. Acesso em: 5 out. 2015.

CÉSAR, Maria Rita de A. Da escola disciplinar à pedagogia do controle. 2004. 190 f. Tese (Doutorado em Educa- 
ção) - Faculdade de Educação, Universidade Estadual de Campinas, Campinas, 2004.

Gênero, sexualidade e educação: notas para uma epistemologia. Educar em revista, Curitiba, n. 35, p. 37-51, set./dez. 2009.

Quatro Intervenções para uma pedagogia queer. In: REUNIÃO ANUAL DA ASSOCIAÇÃO NAIONAL DE PÓS-GRADUAÇÃO E PESQISA EM EDUCAÇÃO (ANPeD), 31., 2008, Caxambu, MG. Anais... Caxambu, MG: ANPeD, 2008.

CANDAU. Vera M. Construir ecossistemas educativos, reinventar a escola. In: Petrópolis, RJ: Vozes, 2002. p. 11-16.

(Org.). Reinventar a escola.

CANOAS. Poder Executivo. Decreto no 37, de 28 de janeiro de 2015. Dispõe sobre o tratamento nominal, inclusão e uso do nome social de travestis e transexuais nos registros municipais relativos aos serviços públicos prestados no âmbito do poder executivo municipal e dá providências. Canoas, RS, 2015. Disponível em: $<$ https://leismunicipais. com.br/a/rs/c/canoas/decreto/2015/4/37/decreto-n-37-2015-dispoe-sobre-o-tratamento-nominal-inclusao-e-uso-do-nome-social-de-travestis-e-transexuais-nos-registros-municipais-relativos-aos-servicos-publicos-prestados-no-ambito-do-poder-executivo-municipal-e-da-providencias>. Acesso em: 05 out. 2015.

EU sou homem. Direção: Márcia Cabral. São Paulo: Prefeitura Municipal de São Paulo/ Coletivo de Lésbicas Feministas/Coletivo Minas de Cor, 2008. 1 DVD (23min), color.

FORTALEZA. Secretaria Municipal de Educação de Fortaleza. Portaria n⿳0 03/2010, de 04 de janeiro de 2010. Fortaleza, 2010. Disponível em: <http://www.sme.fortaleza.ce.gov.br/files/portaria_03_2010.pdf $>$. Acesso em: 5 out. 2015.

FOUCAULT, M. História da sexualidade I: a vontade de saber. Rio de Janeiro: Graal, 1984.

Segurança, território e população. São Paulo: Martins Fontes, 2008.

FURLANI, Jimena. Mulheres só fazem amor com homens? A educação sexual e os relacionamentos entre pessoas do mesmo sexo. Proposições, Campinas, v. 19, n. 2, p. 111-131, maio/ago. 2008. Disponível em: <http://www. scielo.br/scielo.php?script $=$ sci_arttext\&pid $=$ S0103-73072008000200009\&lng $=$ pt\&nrm $=$ iso \&tlng $=$ pt $>$. Acesso em: 05 out. 2015.

GALLO, Sílvio. Uma apresentação: diferenças e educação: governamento e resistências. In: LOPES, M. C.; HATTGE, M. D. (Org.). Inclusão escolar: conjunto de práticas que governam. Belo Horizonte: Autêntica, 2009. p. 29-41.

GOIÁS. Conselho Estadual de Educação. Resolução CEE/CP no 5, de 03 de abril de 2009. Goiânia, 2009a. Disponível em: <http://www.cee.go.gov.br/wp-content/uploads/2009-Resolu\%C3\%A7\%C3\%A3o-CP-051.pdf>. Acesso em: 05 out. 2015.

Conselho Estadual de Educação. Parecer no 4, de 03 de abril de 2009. Goiânia, 2009b. Disponível em: $\overline{<\mathrm{http}: / /}$ www.cee.go.gov.br/wp-content/uploads/ Parecer-CEE-CP-N-4-2009-Nome-social-de-travestis-e-transexuais. pdf $>$. Acesso em: 05 out. 2015.

LOURO, G. L. Um corpo estranho. Ensaios sobre sexualidade e teoria queer. Belo Horizonte: Autêntica: 2004.

MARTINELLI, Maria Lúcia (Org.). Pesquisa qualitativa: um instigante desafio. São Paulo: Veras, 1999.

PARÁ. Secretaria de Estado de Educação. Portaria no 016/2008 - GS. Belém, 10 abr. 2008. Disponível em: <http:// www4.seduc.pa.gov.br/prematricula/016-2008.pdf>. Acesso em: 05 out. 2015.

PERES, William S. Travestis: subjetividade em construção permanente. In: UZIEL, Anna Paula; RIOS, Luis Felipe; PARKER, Richard G. (Org.). Construções da sexualidade: gênero, identidade e comportamento em tempos de Aids. Rio de Janeiro: IMS/UERJ/Abia, 2004. p. 78-96.

PERRENOUD, Philippe. 10 novas competências para ensinar. São Paulo: Artmed, 2007.

RIO DE JANEIRO (Estado). Universidade Federal Rural do Rio de Janeiro. Secretaria dos Órgãos Colegiados. Deliberação no 43, de 29 de julho de 2014. Seropédica, RJ, 2014. Disponível em: <http://www.ufrrj.br/soc/DOCS/ deliberacoes/consu/Deliberacoes_2014/Delib043CONSU2014.pdf>. Acesso em: 05 out. 2015.

RIO GRANDE DO NORTE. Poder Executivo. Decreto no 22.331, de 12 de agosto de 2011. Dispõe sobre o direito ao uso de nome social por pessoas travestis e transexuais no âmbito da Administração Pública Direta e Indireta do Estado do Rio Grande do Norte. Natal, 2011. Disponível em: <http://adcon.rn.gov.br/ACERVO/gac/DOC/ 
DOC000000000064655.PDF>. Acesso em: 05 out. 2015.

SALA, Ariana. Escolarização de travestis e transexuais no Brasil. Documento técnico contendo diagnóstico da situação educacional de travestis e transexuais, apontando possibilidades de ações articuladas junto a programas do Ministério da Educação e aos sistemas de ensino voltados à formação básica, profissional e superior. Brasília, DF: OEI, 2014.

SÃO PAULO (Estado). Conselho Regional de Medicina do Estado de São Paulo. Resolução n 208, de 27 de outubro de 2009. Diário Oficial do Estado de São Paulo, Poder Executivo, São Paulo, SP, 11 nov. 2009. Seção 1, p. 168.

SER mulher. Direção: Luciano Coelho. Curitiba: Projeto Olho Vivo, 2007. 1 DVD (50 min), color.

SILVA, Tomaz Tadeu da. Documentos de identidade: uma introdução às teorias do currículo. 2. ed. Belo Horizonte: Autêntica, 2007.

SULLIVAN, Andrew. Praticamente normal: uma discussão sobre o homossexualismo. São Paulo: Companhia das Letras, 1996.

SWAIN, Tânia Navarro. Heterogênero: uma categoria útil de análise. Educar em revista, Curitiba, n. 35, p. 23-36, set./dez. 2009.

TRANSEXUAL ganha na Justiça o direito a mudar de nome sem cirurgia de sexo. Gazeta do Povo, Curitiba, $p$. 8, 08 jan. 2009.

VIDAL, D. G. Educação sexual: produção de identidade de gênero na década de 1930. In: SOUZA, C. P. (Org.) História da Educação. Processos, práticas e saberes. São Paulo: Escrituras, 2002. p. 87-104.

VITÓRIA. Prefeitura Municipal de Vitória. Lei no 8.585, de 05 de dezembro de 2013. Dispõe sobre os parâmetros para inclusão do nome Social de Travestis e Transexuais nos registros escolares das escolas do sistema municipal de Ensino de Vitória-ES. Vitória, ES, 2013. Disponível em: <http://www.vitoria.es.leg.br/Arquivo/Documents/ legislacao/html/L85852013.html>. Acesso em: 05 out. 2015.

VITÓRIA DA CONQUISTA. Poder Executivo. Decreto $\mathbf{n}^{\mathbf{0}} \mathbf{1 4 . 2 7 3}$, de 14 de fevereiro de 2012. Institui o uso do nome social às pessoas travestis e transexuais nos órgãos da Administração Pública Municipal Direta, Indireta, Autarquias, Fundações, nas Instituições Públicas Municipais de Ensino da Cidade de Vitória da Conquista. Vitória da Conquista, 2012. Disponível em: <http://ba.portaldatransparencia.com.br/prefeitura/vitoriadaconquista/?pagin $\mathrm{a}=$ abreDocumento\&arquivo=35E805508948> . Acesso em: 5 out. 2015.

Recebido em: 30.10 .2015

Aprovado em: 03.03.2016 